\title{
Dynamic Models of Deformation of Crustal Blocks in the Area of Development of Coal Deposits - the Basis of the Information Security of Their Development
}

\author{
Solovitskiy Aleksandr N. \\ T. F. Gorbachev Kuzbass State Technical University, 28 street Vesennyaya \\ Kemerovo 650000, Russian Federation \\ e-mail: san.mdig@mail.ru
}

\begin{abstract}
It is found that transition to new, safe and environmentally harmless technologies of the development of coal deposits in Kuzbass is not possible without the development of new models of dynamic deformation of crustal blocks. For their implementation the registration kinematics theory of crustal blocks was advanced, unified integrated strain state parameters of crustal blocks were established. In traditional technologies, the registration is based on either movement amplitudes of the surface of the earth crust or instrumental accuracy. Besides, a pattern of registration of the kinematics of crustal blocks is determined to identify the tensely deformed state. Based on the parameters of the block structure of the earth crust there is a list of parameters as recorded and produced by the geodesic monitoring of the stress-strain state of the earth crust. Zoning was evolved for practical use of dynamic models of deformation of crustal blocks, and geodynamic hazard assessment during the development of coal deposits was based on this zoning. This approach not only provides the multiplicity and complexity of using information but also increases its accuracy.
\end{abstract}

Keywords - Block Earth's crust, rank, geodynamic phenomenon, kinematics, geodynamic polygon, dynamic models of deformations.

\section{INTRODUCTION}

Currently, the development of coal deposits in Kuzbass is characterized by increasing volume of coal production (more than 210 million tons per year) and the introduction of new, safe and environmentally friendly technologies. The implementation of these technologies cannot be realized without studying of geodynamic and techno genic processes during the development of mineral resources, as the received information about them is an essential aspect of the security and the forecast of catastrophic geodynamic phenomena: rock bursts, sudden outbursts, earthquakes [1, 2] . Therefore, the development of theory and methods for creating dynamic models of crustal deformation units in the areas of development of coal deposits is relevant; it also has scientific and practical interest within the reception of the information about these processes $[3,4,5]$. The aim of this research is to develop dynamic models of the earth's crust deformations in the development of coal deposits in Kuzbass to ensure information security.
Scientific novelty of the presented work is as follows:

1. The improvement of technology of the GDP constructions and the establishment of dependence of accuracy of registration of the kinematics of crustal blocks at their locations on the reliability of the account of slow velocity crustal deformation, which do not lead to the appearance of life threatening situations.

2. The exclusion of ambiguity kinematic characteristics of crustal blocks used in the traditional technology that enables the use of analytical functions with the life threatening situation manifestation parameters.

3. The provision of information interaction between geodesy, geodynamics, geomechanics and geotechnology in the development of mineral resources on a common theoretical basis and common parameters.

The theoretical significance of the research is to optimize the registration of kinematics crustal blocks to determine the dynamic parameters and their interpretation, ensuring the expansion of information exchange between the adjacent earth sciences.

The practical significance of the research is to use the research results to solve some problems of geodesy, geodynamics, geomechanics and geotechnology in the development of mineral resources, providing risk reduction and mitigation of manifestations of life threatening situations in the areas of construction and operation of more than 130 coal-mining enterprises of Kuzbass.

\section{THE OBJECT OF STUDY.}

The object of the research is the dynamic models of crustal deformation. It is impossible to provide them with the classical study of traditional methods of geomechanics, mine surveying and geodesy $[6,7,8,9]$. Traditional technologies of repeated geodetic and gravimetric observations on geodynamic polygons (GDP) in the areas of development of coal deposits are currently focused on the study of the deformation of the Earth's surface through the use of flat patterns of its sites, which do not provide adequacy to blocks of an earth's crust $[6,7,8,9]$. Therefore, the development of 
theory and methods of dynamic models of the earth's crust deformations in the development of Kuzbass coal deposits with a view to the safety of their development is a scientific problem, which has great socio-economic importance. The solution of this problem requires the development of new mathematical models considering not only the definition and recording of the current state of deformation of crustal blocks in the areas of development of coal deposits but also the registration of their kinematics. Such models are dynamic, as they reflect the actual state of deformation of crustal blocks in the areas of development of coal deposits in space and time. The establishment of common integrated parameters of the deformed condition of crustal blocks is required for their formation; their determination is based on registration of required kinematic characteristics of the test units with a view to ensuring the adequacy of their configuration, hierarchy, interaction, and geodynamic activity. The practical use of dynamic models of crustal deformation is to evaluate the geodynamic hazards during the development of coal deposits; the quantitative measure of it is a geodynamic risk.

\section{MATERIALS AND METHODS}

The theory of registration of kinematics of the Earth's crust block is based on the criterion of slow speeds of crustal deformations, which do not lead to the appearance of life threatening situations and determining the variables of the dynamic model of its deformation [10, 11]. Kinematic characteristics of modern movements of the Earth's surface are currently used in traditional technologies of collecting information. These characteristics do not reflect the change in the deformed condition of the structural elements of the crust, and they do not have the analytical relationships with parameters of manifestations of geodynamic phenomena (life threatening situations) $[12,13]$. The spatial structural model of cell constructions of geodynamic polygon is proposed for registration of progress of natural and technogenic geodynamic processes of crustal blocks; this model is based on the directly proportional to the mean-square error of measurement of the rate of change of crustal deformation units in time per year, which do not lead to the appearance of life threatening situations (less than $1 \cdot 10-6$ year ). Registration of these processes requires a complex improvement of the global navigation satellite technology and improvement of its accuracy $[14,15]$.

The following method has been proposed to establish a criterion of accuracy of registration of kinematics crustal blocks in the area of development of a particular field.

The changes of deformation of their kinematics in time are modeled for the study of crustal blocks rank in the area of development of deposits. Based on these dependencies the speed of these units per year is determined, which describes their geodynamic activity (Table 1).

The structural model of the spatial constructions of GDP for every crustal block under the study as a unit cell was proposed to implement a radical improvement of the collection of information to build dynamic models of crustal deformation at the development of coal deposits of Kuzbass.
It is especially important for development of coal deposit areas, as in this case, the object of study becomes the changes in strain state of a block of rock mass. Since the state of pristine rock mass has been formed in the recent period, therefore, the theoretical basis of this transition is the hypothesis of the continuity of the latest movements in the modern period.

TABLE 1 - Indices of exactness of determination of coordinates and heights on the points of the structurally oriented constructions of GDP

\begin{tabular}{|l|c|c|}
\hline $\begin{array}{l}\text { The rank of a } \\
\text { crustal block }\end{array}$ & $\begin{array}{c}\text { The speed of the } \\
\text { Earth's crust block, } \\
\text { mm / year }\end{array}$ & $\begin{array}{c}\text { The errors of } \\
\text { determination of } \\
\text { coordinates and heights, } \\
\text { mm }\end{array}$ \\
\hline II & 158 & \pm 38 \\
\hline III & 40 & $\pm 9,5$ \\
\hline IV & 17 & $\pm_{4,1}$ \\
\hline V & 12,3 & $\pm_{3,0}$ \\
\hline VI & 2,8 & $\pm_{0,7}$ \\
\hline
\end{tabular}

The indicated model of cell of constructions of GDP was offered for realization of this hypothesis. Such constructions of the GDP are directly dependent on the interaction of crustal blocks with the faults field. The minimum number of mobile items for each of them must not be less than 4, with dependency in the top of the sites and crossing the fractures in the light of the depth of penetration (fig. 1).

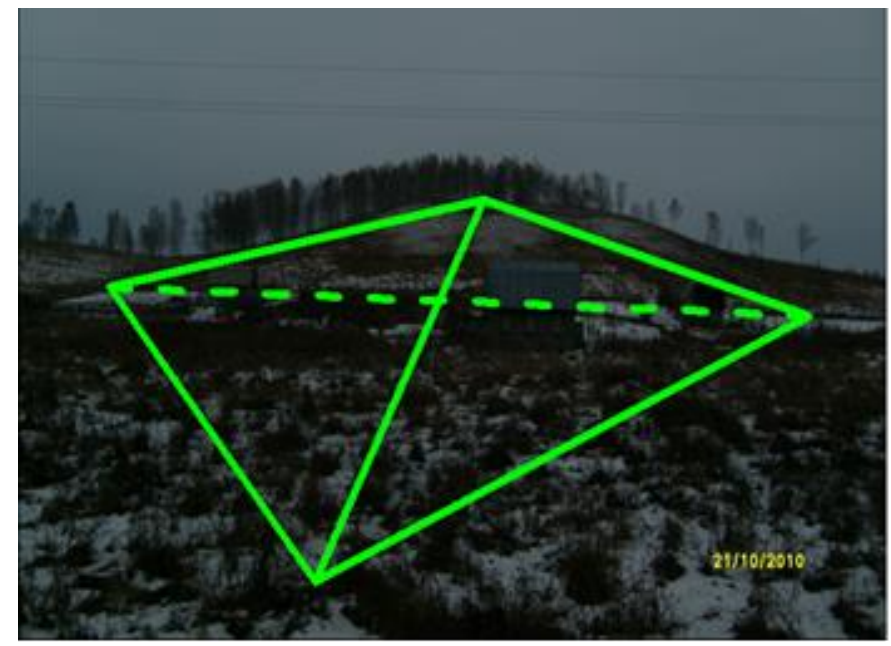

Fig. 1. Structural spatial model of cell construction GDP

This approach provides flexibility of these constructions, it also evaluates the changes of deformation in time not only in a plane, but at a depth $\mathrm{h}$, characterizing the center of gravity of the building.

As a result of the author's research, it was found that the most common figure GDP constructions in Kuzbass will be the tetrahedron (the analogue of the standard flat figure - the central system). The form of such a system will be determined by the highest point of a located block of the crust and the intersection of the fault (see Fig. 1). This approach of 
collecting information about the kinematics of the Earth's crust block on the basis of the proposed model GDP constructions is characterized not only by a succession of ensuring the rigidity of the network but also the qualitative improvement. Quality improvement means the location of the items on the commanding heights and in faults of the intersection nodes, as well as providing appropriate forms of network configuration blocks of the crust, when the angles in the proposed constructions GDP may differ significantly from the recommended regulations of traditional networks, while the length of the sites is determined by the size of the earth's crust block, according to their hierarchy, not the network class. It is clear that the structural spatial model of the unit of GDP constructions differs from the traditional in different heights, and the depth of laying the points.

The theory of registration of kinematics of earth crust block provides the definition of the variables of the dynamic model of deformation $[10,11]$. Due to the differences of the values of the speeds of movements of crustal blocks of different ranks from the same values of changes in time strain, such kinematic characteristics of crustal blocks cannot be taken as variables of the dynamic model of deformation of crustal blocks. A more acceptable option for these variables are the changes of the deformations of the units of the earth's crust in time, which are integral characteristics. These are dynamic parameters (changes in time deformation (stress) and potential energy, causing the kinematics of the Earth's crust block).

The basis of their determination is the connection of its movements with the components of the strain tensor, which is described using Cauchy equations. Dynamic parameters of crustal blocks were proposed to determine sequentially in four stages. At the first stage the changes of deformation of structurally oriented constructions GDP in time are obtained as a linear function, when it is assumed that the displacement of points laid down in the earth's crust block is equal to the change of coordinates $\Delta \mathrm{X}[\mathrm{t}-\mathrm{t} 0], \Delta \mathrm{Y}[\mathrm{t}-\mathrm{t} 0], \Delta \mathrm{H}[\mathrm{t}-\mathrm{t} 0]$ relevant to the coordinate axes of the rectangular system. In matrix form, this equation has the form

$$
\mathrm{R}[\mathrm{t}] \mathrm{D}[\mathrm{t}-\mathrm{t}]=-\Delta \mathrm{R}[\mathrm{t}-\mathrm{t}]
$$

where $\mathrm{D}[\mathrm{t}-\mathrm{t}]$ - components of the tensor of the 2nd rank [e $[\mathrm{t}-\mathrm{t}]] ; \mathrm{R}[\mathrm{t}]$ - coordinates of points ((X[t ], Y $[\mathrm{t}], \mathrm{H}[\mathrm{t}]) ; \Delta \mathrm{R}$ $[\mathrm{t}-\mathrm{t}]$ - the change of the coordinates in time for period $\mathrm{t}-\mathrm{t}$

In general, solution of the system of linear equations (1) according to the least square method is expressed as:

$$
\mathrm{D}[\mathrm{t}-\mathrm{t}]=-\mathrm{R}[\mathrm{t}] \Delta \mathrm{R}[\mathrm{t}-\mathrm{t}]
$$

\section{where $\mathrm{R}[\mathrm{t}]$ - inverse matrix $\mathrm{R}[\mathrm{t}]$.}

The system of 12 normal equations (for the number of points $\mathrm{n}=4$ ) is composed to find the 12 unknowns in (1). These equations are a linear relationship between the radius vector of the items laid down in the earth's crust block, and accordingly the radius vector of the displacement, the coefficients e [t-t ] will be components of the tensor of the 2nd rank.

These 9 values $\mathrm{e}[\mathrm{t}-\mathrm{t}]$ in the solution (1) are the components of an asymmetric tensor of the second rank. To find the principal values of strain $\varepsilon 1[\mathrm{t}-\mathrm{t} 0], \varepsilon 2[\mathrm{t}-\mathrm{t} 0], \varepsilon 3[\mathrm{t}-\mathrm{t} 0]$ expression vector of the matrix (2) is represented as follows:

$$
(\mathrm{D}[\mathrm{t}-\mathrm{t}]-\mathrm{D} 0) \mathrm{X}[\mathrm{t}]=0
$$

where D0 =lEM; l-own (main) value; EM - unit diagonal matrix.

Also at the first stage, the components of the change in time of angular deformities $\Delta \gamma[\mathrm{t}-\mathrm{t}], \Delta \gamma[\mathrm{t}-\mathrm{t}]$ и $\Delta \gamma[\mathrm{t}-\mathrm{t}]$ are determined, which characterize the distortion of angles between the directions parallel to the respective axes, as well as the relative change of volume $\theta[\mathrm{t}-\mathrm{t}]$ (dilatation) of crustal blocks in time. These components of the tensor of the second rank will be assigned to the center of gravity of the spatial geometric shape composed of structurally oriented items constructions of GDP. At the second stage, the relevant changes of normal $\Delta \mathrm{e}[\mathrm{t}-\mathrm{t}]$ and shear $\Delta \mathrm{s}[\mathrm{t}-\mathrm{t}]$ stress in time are defined by the obtained time-strain $\Delta \mathrm{t}[\mathrm{t}-\mathrm{t}]$ on the basis of a generalized Hooke's law. Table 2 shows an example of values of the component changes of the deformation of crustal blocks in the VI rank in the area of mine "Kedrovskiy" and GPS for their determination in time.

TABLE 2 - The variation of the components of deformations of crustal blocks in time and mean-square errors of their determination

\begin{tabular}{|c|c|c|c|}
\hline $\mathbf{e}_{\mathbf{i j}}\left[\boldsymbol{t}-\boldsymbol{t}_{\mathbf{0}}\right]$ & Value & $\boldsymbol{m e}_{\mathrm{ij}}\left[\boldsymbol{t}-\boldsymbol{t}_{\mathbf{0}}\right]$ & Value \\
\hline $\mathrm{e}_{11}$ & $-6.3 \cdot 10^{-6}$ & $m \mathrm{e}_{11}$ & $3.4 \cdot 10^{-7}$ \\
\hline $\mathrm{e}_{12}$ & $4.3 \cdot 10^{-5}$ & $m \mathrm{e}_{12}$ & $3.6 \cdot 10^{-7}$ \\
\hline $\mathrm{e}_{13}$ & $4.6 \cdot 10^{-3}$ & $m \mathrm{e}_{13}$ & $6.2 \cdot 10^{-6}$ \\
\hline $\mathrm{e}_{21}$ & $-5.9 \cdot 10^{-7}$ & $m \mathrm{e}_{21}$ & $1.6 \cdot 10^{-7}$ \\
\hline $\mathrm{e}_{22}$ & $2.3 \cdot 10^{-4}$ & $m \mathrm{e}_{22}$ & $6.3 \cdot 10^{-7}$ \\
\hline $\mathrm{e}_{23}$ & $3.6 \cdot 10^{-3}$ & $m \mathrm{e}_{23}$ & $2.7 \cdot 10^{-6}$ \\
\hline $\mathrm{e}_{31}$ & $-3.8 \cdot 10^{-5}$ & $m \mathrm{e}_{31}$ & $1.7 \cdot 10^{-6}$ \\
\hline $\mathrm{e}_{32}$ & $2.7 \cdot 10^{-4}$ & $m \mathrm{e}_{32}$ & $1.6 \cdot 10^{-6}$ \\
\hline $\mathrm{e}_{33}$ & $4.3 \cdot 10^{-3}$ & $m \mathrm{e}_{33}$ & $3.0 \cdot 10^{-5}$ \\
\hline
\end{tabular}

At the third stage, the evaluation of the accuracy of the changes of deformation of components in time is realized. At 
the fourth stage, the time variation of the potential energy of deformation $\mathrm{dE}[\mathrm{t}-\mathrm{t} 0]$ of crustal blocks is determined, the amount of it is equal to $\mathrm{V}$. The proposed algorithm in a single cycle allows detecting consistently the entire spectrum of the dynamic parameters of the block of the crust under the test. It is implemented with the algorithmic language QBASIC PC, programming «BM», it has the certificate of the state registration.

The range of the dynamic parameters of the Earth's crust block characterizes the dynamic variables of its model, where the theoretical basis is the following fundamental hypothesis: an account of the slow speeds of crustal deformation with an accuracy not less than 3•10-6 per year, which do not lead to the manifestation of geodynamic phenomena and the continuity of the latest movements in the modern period. These variables are defined with regard with the following restrictions:

- linear dependence of relationship coordinates changes with its components of the strain tensor;

- presentation of the blocks of the crust under the test in the form of elementary infinitesimal quantities.

Thus, these theories were developed to determine the variables of dynamic models of crustal deformation units:

- theory of registration of the kinematics of the block of the crust of the latest period, justifying the dependence of determining the coordinates and altitudes of mobile constructions GDP points in one period of the rank of crustal blocks;

- theory and technology of determination of the dynamic parameters of the Earth's crust in the area of the field unit is based on:

1) their direct proportion to the horizontal and vertical movements of the points of the GDP and their coordinates in the initial epoch;

2) their targeting, that is allocable to the center of gravity of each block of the earth's crust, situated in the depths of the rock mass;

3) a rigorous mathematical treatment of the results of repeated observations, characterized by uniqueness, typing and reliability;

4) the developed and implemented algorithms and software for PCs for their consistent determination and assessment of accuracy: first, changes the deformations in time, and then the stress and potential energy.

The author developed the theory of the practical application of dynamic models of the earth's crust block in the development of the deposit area, the purpose of which is to ensure information exchange between geodesy, geodynamics, geomechanics and geotechnology in the development of mineral resources on a common theoretical basis and common parameters $[10,11,16,17,18,19,20]$. For its implementation the classification was proposed, which is based on zoning, it is a universal method in the Earth sciences. Indicators of zoning are dynamic parameters of crustal blocks that emphasize their integral character. Two methods of zoning are proposed:

- zoning of crustal blocks on the degree of danger of their deformation;

- functional zoning of the development of strains of crustal blocks;

- assessment of the possible risk of life threatening situations during the development of the deposit

The theoretical basis for the implementation of the degree of hazard zoning of crustal blocks is the fundamental hypothesis of the registered speeds of slow crustal deformation, which do not lead to the manifestation of geodynamic phenomena. According to the degree of danger of deformation of the crust blocks, it is proposed to divide them into four groups (classes):

- Ist -geodynamic inactive block of the earth's crust (GIAB $\mathrm{EC})$;

- IInd - geodynamic activity block of the earth's crust (GAB EC);

- IIIrd - GAB EC, where a hotbed of geodynamic phenomena is formed;

- IVth - GAB EC, where a hotbed of geodynamic phenomena is formed, it provides an assessment of energylimiting (or the manifestation of the incident of life threatening situations).

The criterion for identifying GAB EC during the zoning is the fulfillment of the condition:

$$
\mathrm{Ve}[\mathrm{t}-\mathrm{t}] 3 \mathrm{Ve}[\mathrm{t}-\mathrm{t}] \text {, }
$$

where $\mathrm{Ve}[\mathrm{t}-\mathrm{t}]$ - the rate of deformation of the investigated crustal block per year;

$\mathrm{Ve}[\mathrm{t}-\mathrm{t}]-$ the rate of deformation of the crust, which does not lead to the manifestation of geodynamic phenomena, it is equal $1 \cdot 10$ year.

The basis of this criterion is the fundamental hypothesis of the evaluation of slow strain rate of crustal blocks that do not lead to the appearance of life threatening situations.

Methods of crustal blocks zoning according to the danger of deformation in the area of the deposit caused by the combined effect of natural and technogenic geodynamics during the period of repeated observations on the ODS, are the following [17].

1. Determination of the dynamic parameters of the Earth's crust block Д [ $\mathrm{t}-\mathrm{t}$ ] for the period $\mathrm{t}-\mathrm{t}$ (for "BM" program), the calculation of the values of their changes in time per year.

2. Determination of the risk of developing deformations of the earth's crust block, which is set by the amount of the changes of dynamic parameters in time: I-st degree of danger - the changes of deformation of components in time less than $3 \cdot 10$ per year. II-nd degree of danger - the changes of deformation of components in time more than $3 \bullet 10$ per year .; 
III-rd degree of danger - changes of deformation of components in time from $15 \cdot 10$ to $22,4 \cdot 10$ year ; IV-th degree of risk - changes deformation component in time more than $22,4 \cdot 10$ per year.

Functional zoning of crustal deformation units at the preliminary stage allows solving of the following geomechanical tasks ensuring geotechnology of mineral exploration:

1. To establish order and systems of development.

2. To orientate the directions of capital mine workings.

3. To plan the speed of face advance and other technological parameters.

4. To manage the rock pressure.

Functional zoning of crustal deformation units at the stage of development of the field is the next stage of their learning and it is held in GAB EC. The solution of such problems cannot be solved by widespread traditional methods (widths, cross-sections, shifts and other changes). Therefore, different solutions are available, which include:

- definition of the type of geodynamic situation;

- monitoring changes of the main directions of deformation of crustal blocks over time; time;

- ranking changes of deformation of crustal blocks over

- control the accumulation of potential energy of deformation of crustal blocks.

On the basis of zoning, the author developed the risk assessment of the possible manifestations of life threatening situations during the development of coal deposits [17]. The theoretical basis of it is the fundamental hypothesis of intensification of development of deformations of crustal blocks under the influence of intensive anthropogenic processes. This revitalization of the development of deformations of crustal blocks is determined not only by geological conditions of the deposit, but also by the scale and intensity of its development.

Risk assessment of this manifestation includes an expert analysis of the danger degree (D) and vulnerability (V), which is expressed by the risk factor ( $\mathrm{R})$

$$
\mathrm{R}=\mathrm{DV}
$$

Based on a quantitative risk assessment, the well-known approach of obtaining normalizing coefficients, characterizing the proportion of the most unfavorable situation, taken as a unit, was adopted. Integral codes for indicators of danger and vulnerability are formed for the definition of these coefficients. Risk assessment of the possible manifestations of life threatening situations of a destructive nature during the development of the coal field is involved.
1. Definition based on expert analysis of the integral code (figures A, B, C and D), which characterizes the degree of danger.

2. Definition based on expert analysis of the integral code (figures $\mathrm{D}, \mathrm{K}$ and $\mathrm{L}$ ), which characterizes the degree of vulnerability.

3. Determination of the normalizing coefficient $\mathrm{D}$, which characterizes the degree of danger

$$
\mathrm{O}=\sum \mathrm{pi} \alpha \mathrm{i} \alpha 0
$$

where pi - weight - i-th hazard indicator (for figures A, B, $\mathrm{C}$ it is assumed to be 0.2 , and for $\mathrm{D}-0.4)$; $\alpha \mathrm{i}$ is the value of the $\mathrm{i}$-th code danger index (A, B, C and D); $\alpha 0$ - normalizing multiplier.

4. Determination of the normalizing factor $\mathrm{V}$, characterizing the degree of vulnerability,

$$
\mathrm{V}=\sum \text { pi } \alpha \mathrm{i} \alpha 0
$$

where pi - weight of the i-th vulnerability index (for D pi = $0.5, \mathrm{~K}-0.3$ and $\mathrm{L}-0.2)$; $\alpha \mathrm{i}$ is the value of the $\mathrm{i}$-th code vulnerability index (D, K, L); $\alpha 0$ - normalizing multiplier.

5. Determination of the possible risk factor is carried out according to (5).

6. The degree of risk manifestations of life threatening situations is determined by $\mathrm{P}$ (small - less than 0.15 ; moderate - from 0.15 to 0.3 , large - from 0.3 to 0.5 : critical - more than $0.5)$.

\section{RESULTS AND DISCUSSION}

The integrated risk assessment of the possible manifestations of life threatening situations was performed for four mines by the method (5). The investigated mines are characterized by location in different parts of Kuzbass and the geodynamic activity of the earth crust blocks of different ranks (for mine "Koksovaya" and LLC "Mine Office "Karagailinskoe" - block of the crust of the fourth rank, and in the earth crust block V-rank for mines "Butovskaya" and "Krasnoyarskaya" - V-th rank). It is presented in table 3.

TABLE 3 - The degree of possible risk of manifestation of life threatening situations in four mines of Kuzbass

\begin{tabular}{|l|c|c|}
\hline Mine & P & $\begin{array}{c}\text { The possible risk of } \\
\text { manifestation of life } \\
\text { threatening situations }\end{array}$ \\
\hline "Koksovaya" & 0,35 & Large \\
\hline "Krasnoyarskaya" & 0,12 & Small \\
\hline $\begin{array}{l}\text { LLC Mine Office } \\
\text { "Karagailinskoe" }\end{array}$ & 0,35 & Large \\
\hline "Butovskaya" & 0,26 & Moderate \\
\hline
\end{tabular}




\section{CONCLUSIONS}

Based on the results of the research the following conclusions were made:

1. It was found that the study of the changes of deformation of crustal blocks in time in the areas of development of deposits using the traditional methods of geomechanics, mine surveying and classic geodesy is impossible.

2. The theory of kinematics of registration crustal blocks and variable definitions of dynamic models of crustal blocks was developed.

3. It was established that the main difference of the spatial structural model of the GDP is providing the determination of the dynamic parameters of crustal blocks in a sub horizontal plane, but also at a depth $\mathrm{h}$, which characterizes the center of gravity of the construction.

4. The practical use was developed of dynamic models of crustal blocks providing transition to new, safe and environmentally-friendly technology of development of coal deposits on the basis of:

- zoning of crustal blocks on the degree of danger of their deformation;

- functional zoning of the development of strains of crustal blocks;

- assessment of the possible risk of manifestation of life threatening situations during the development of the deposit.

\section{REFERENCES}

[1] Instructions for safe mining operations at ore and non-metallic deposits, objects of construction of underground structures prone to and dangerous in rock bumps. 2000. Moscow, SE STC on industrial safety of Federal Committee for Mining and Industrial Supervision of Russia, pp: 66.

[2] Kopytov A. I, Eremenko V.A., Matveev I.F. Selection of safe technology of development of prone and dangerous rock bumps deposits of iron ore Evrazruda. Vestnik kuzbasskogo gosudarstvennogo tehnicheskogo univeristeta [Vestnik of Kuzbass State Technical University].. 2013. \#2.

[3] Guidelines for the prevention of rockbursts, given the geodynamics of mineral deposits, 1983. Leningrad, VNIMI, 1983. pp: 118.

[4] Zykov V. S. Factors and properties of the mountain range defining the hazards of geodynamic phenomena. Vestnik kuzbasskogo gosudarstvennogo tehnicheskogo univeristeta [Vestnik of Kuzbass State Technical University]. 2014. \#5.
[5] Sashurin A. D., 2004. Modern geodynamics and the development of accidents on the objects of subsoil use. Geodynamics and stress state of Earth's interior. Novosibirsk, IGD SO RAN.

[6] Bykadorov A. I., Larichkin P. M, Svirko S. V., Renev A. A., 2015 Methods of analysis of the distribution of the process displacement of the earth surface in the development of coal deposits. Vestnik kuzbasskogo gosudarstvennogo tehnicheskogo univeristeta [Vestnik of Kuzbass State Technical University].2015. \#6.

[7] Kaftan A. I., Krasnoperov R. I., Jurowski P. P., 2010. Graphical representation of the results of the determination of movements and deformations of earth's surface by means of global navigation satellite systems. Geodesy and cartography.\#1.

[8] Kolmogoro, V. G., 2012. The study of stress-strain state of the earth's surface as a result of repeated high-precision leveling. Vestnik of SGGA, \#1..

[9] Serebryakova L. I., 2013. The methodological guide for the geodynamic research in the system of Federal registration service. Geodesy and cartography, \#10.

[10] Kalenitskiy A. I., Solovitski A. N., 2012. The peculiarities of technology of studying changes of the deformations of the earth crust blocks in time during the development of deposits of Kuzbass. INTERAKSI-GEOSIBERIA.-2012. Novosibirsk, SSGA.

[11] Karpik A. P., Kalenitskiy A. I., Solovitski A. N., 2013. The technology of studying the changes of the deformations of the earth crust blocks in time during the development of deposits of Kuzbass. Vestnik of SSGA. \#4.

[12] Gerasimenko M. D, 2014. To the question of determining the directions of principal axes of strain] // Geodesy and cartography. \#5.

[13] Savinykh V. P., Pevnev A. K., Yambaev H. K., 2013. The elastic rebound theory, dilatancy, geodesy forecast. Izv. Vuzov "Geodesy and aerophotography", \#5.

[14] Varialility of GPS/GLONASS differential code baises/ A. A. Mylnikova, Yu. V. Yasyukevich, E. V. Kunitsyu [te al] //Results in Physics. 2015, Vol. 5.

[15] Karpik A. P., Ganagina I. G., Kosarev S. N., Goldobin D. N.,2016. Navigation and information system of precise transport positioning using the ground infrastructure GLONASS // Gyroscopy and Navigation, Vol. 7, \#1.

[16] Solovitskiy A. N., 2012. About features of forming the system for deformation monitoring of earth crust blocks during the development of the coal deposits of Kuzbass. Geodesy and cartography. \#10.

[17] Solovitskiy A. N., 2012. Assessment of the possible risk of manifestation of geodynamic phenomena in the development of deposits of Kuzbass. Natural and intellectual resources of Siberia. - Kemerovo, Vol. 1.

[18] Kozyrev A. A., Semenova I. E., Rybin V.V. and Avetisyan I. M. Stress redistribution in deep open pit mine zhelesny at kovdor iron deposit. Journal of Mining Science, 2015, Volume 51, \#4.

[19] Saksin B. G., Rasskazov I. Y., and Shevchenko B. F.. Principles of integrated analysis of modern stresses and statins in the outer otust of the Amurian plate. Journal of Mining Science, 2015, Volume 51, \#2.

[20] Kocharyan G. G. and Ostapchuk A. A.. Acoustic emission during different-type inter-block movements. Journal of Mining Science,2015. Volume 51,\#1. 